\title{
'A Doctrine Quite New and Altogether Untenable': Defending the Beneficiary Pays Principle
}

\section{Daniel Butt}

\section{Introduction}

This article defends and explores a version of the "beneficiary pays" principle: the claim that the involuntary receipt of benefits stemming from injustice can, in some circumstances, give rise to rectificatory obligations to the victims of the injustice in question. It considers how arguments in favour of this claim can best be advanced, given contrasting reactions to hypothetical examples which seek to draw out the normative principles at stake. The "beneficiary pays" principle has been put forward as a way of arguing for the existence of remedial or compensatory obligations in a range of real world policy cases, including controversies over affirmative action; reparations for historic wrongdoing, such as colonialism; and the costs of mitigating the effects of climate change. ${ }^{1}$ The thought behind the principle is clearly controversial, in that it holds that individuals can come to possess obligations to others through merely receiving, rather than soliciting or accepting, benefits: a claim which many have sought to oppose. ${ }^{2}$ Michael Sandel, for example, relates the indignation of David Hume when charged for repairs to his house which had been undertaken by a contractor without his consent. Hume took the case to court, arguing that permitting such a liability in law would permit tradesmen to go about Edinburgh undertaking repairs wherever they saw fit, and subsequently imposing their bills on unsuspecting property owners. Allowing obligations to arise through the involuntary receipt of an apparent benefit would, Hume argued, reflect "a doctrine quite new and... altogether untenable" ${ }^{3}$ There are indeed good reasons why we should not accept a doctrine which would permit one agent to impose a benefit upon another and then use the coercive power of the state to extract payment . It is important, however, not to allow intuitive responses to cases of this character to colour our responses to the distinct question of whether those who benefit directly from the automatic effects of harmful wrongdoing can thereby acquire moral responsibilities 
to the victims of the wrongdoing in question. This article considers the question of how best to persuade those who are initially sceptical as to whether this is the case.

The article approaches the issue as being a question of corrective or rectificatory justice, rather than as a matter of distributive justice as it is commonly understood, in two particular senses. First, it is concerned with moral agency against a non-ideal backdrop, whereby it is not assumed that the initial distribution of resources prior to the act of wrongdoing is perfectly just, but merely that it is, at most, legitimate. Second, it seeks to assess the moral agency of particular agents, rather than the character of general rules and institutions. The question is that of what a specified agent, who has benefited from an instance of wrongdoing which has caused a setback to the interests of another, should do. This is not the same as whether, for example, states would be justified in taxing the beneficiaries of injustice in order to compensate the victims. This distinction is important for a number of reasons. For one thing, the state is able to think about this question within the context of its ability (and, as many would suggest, its obligation ${ }^{4}$ ) to seek to bring about a particular scheme of distributive justice. It could seek to put in place a just distributive scheme which would obviate the need for rectificatory action, meaning that the distributive effects of the wrongdoing would have been, in Jeremy Waldron's term, superseded. ${ }^{5}$ If, for example, the state were to attempt to implement a version of luck egalitarianism, it might view benefits which are accrued involuntarily from wrongdoing as one instance of the workings of brute luck, which could then be redistributed, along with other benefits which did not originate from the deliberate gambles of appropriately responsible agents. Alternatively, it could seek to rectify wrongdoing in a systemic way, confiscating the fruits of injustice and redistributing them to the victims in a manner that prioritised the most badly affected victims without necessarily maintaining any connection between a given beneficiary and a given victim. Individual agents are not able to affect distributions in such a dynamic fashion; nor are individual states internationally. Instead, this article is concerned with existing societies where, for the most part, costs are left to lie where they fall unless there is a specific reason to hold another party responsible for paying the cost (as in the law of torts), or disgorging a specific financial 
benefit (as in the law of unjust enrichment). On many theoretical accounts, this is not a world of background distributive justice. The article's context is one where individuals and groups live their lives against this distributive backdrop, but nonetheless believe that they have rights and entitlements. I put to one side a range of problems about the extent to which one's actions should seek to bring society closer to one's preferred scheme of distributive justice, ${ }^{6}$ in that I do assume that agents typically have at least some resources under their control to which we might say they have entitlements, even if they should give away more of their resources than they currently do to assist those in desperate need, ${ }^{7}$ and even though they might not actually be entitled to all of these resources were society to bring about a just distribution. My claim is that, within this real world context, individuals and groups can come to possess rectificatory duties to others through involuntarily benefiting from the wrongdoing of others, and they act wrongly if they fail to act upon these duties.

\section{Persuasion in Relation to the Beneficiary Principle}

The first claim which this article defends is as follows:

Beneficiary Principle (BP): Agents can come to possess obligations to lessen or rectify the effects of wrongdoing perpetrated by other agents by benefiting, involuntarily, from the wrongdoing in question.

Significantly, this is an expressly interpersonal claim, which does not maintain in a straightforward way that it is wrong avoidably to benefit from wrongdoing, meaning that one should disgorge benefits one receives with such a provenance, ${ }^{8}$ unless doing so has the effect of lessening or rectifying the effects of the wrongdoing. In addition, the claim is deliberately phrased so that it is an open question whether a given instance of wrongdoing which leads to an involuntary benefit actually does give rise to a rectificatory obligation. Specifically, the BP holds that agents can come to possess rectificatory obligations from involuntarily benefiting from injustice, not that they 
necessarily do whenever they so benefit. What this means is that there are two tasks before anyone who wants to defend the plausibility of the BP: persuasion and limitation. First, they must show what many dispute: that it is possible to acquire rectificatory obligations simply through the involuntary receipt of benefits. Some deny that this is the case; as such, all that a defence of the potential applicability of the BP needs to show is that there is even one possible case where it does seem unambiguously to apply. If the principle is to be practicable, however, the defender must go further, and give some kind of an account of when such rectificatory obligations are in fact generated. Given the plausible claim that there is a myriad of ways in which many people are benefiting from a wide range of injustice, in what specific circumstances do particular agents have duties to others as a result of benefiting from wrongdoing? How can the BP be limited and specified?

The first task, therefore, is that of persuasion: establishing that there are at least some examples where the BP does indeed come into play. How might this be done? One obvious way is to try to think of an example where we believe an agent possesses an obligation to compensate a victim of wrongdoing, and where the only reason we can give for why we feel this to be true is the fact that the individual is benefiting from the wrongdoing in question. It is crucial to the success of this enterprise that the example is one where the agent who benefits is an innocent third party who cannot at the point at which she benefits be said to be guilty of any kind of wrongdoing which would straightforwardly ground a rectificatory obligation. Of course, if we hold that the benefit does create an obligation which the agent does not fulfil she is then no longer innocent, but for the argument to work, it must be the case that she is indeed innocent at the point of benefit. Consider the following example, adapted from an earlier example devised by Robert Fullinwider specifically to oppose the $B P:^{9}$

My neighbour and I both have large, unruly hedges in our gardens. While I am away on holiday, my neighbour hires a topiarist to come and cut her hedge into the shape of an ornamental peacock. She leaves a note describing the work that is to be done, and $£ 1,000$ in 
payment. However, an enemy of my neighbour becomes aware of my neighbour's plan, and substitutes an alternative note instructing the topiarist to cut my hedge. The topiarist arrives and follows the instructions in the note. My neighbour, therefore, is down $£ 1,000$ and still has an unruly hedge, whereas I have an ornamental peacock.

Does it follow from this that I have a moral obligation to pay my neighbour $f 1,000$ ? Fullinwider would argue that I do not. But is this necessarily the case? Since we are seeking to construct an example as favourable to the BP as possible, let us add the following details to the example. Before I went on holiday, I wrote a letter to the very same topiarist, asking her to cut my hedge into the shape of an ornamental peacock while I was away, in exchange for $£ 1,000$. However, I forgot to post the letter. On my return, I see the peacock and am delighted by it. There is a knock at my door. I assume it is the topiarist, wanting to be paid. I open the door with a smile on my face, holding an envelope of cash. It is my neighbour. She explains the situation. She asks if I will give her the envelope. ${ }^{10}$

For some, it is straightforwardly obvious that it would be wrong not to give her the envelope, and that I have acquired rectificatory obligations to her as a result of having benefited from wrongdoing. This is not, however, a universally shared reaction. Presentation of this type of argument to audiences generally proves very divisive: some accept the force of the BP in this case, some strongly deny it. What should we make of this disagreement?

Invoking an example in this way is an exercise in what is sometimes disparagingly called "intuition pumping". More positively, the point can be expressed in Rawlsian terms as a mechanism for seeking to achieve reflective equilibrium: we use a hypothetical example to assess whether it is possible to construct a coherent set of principles stemming from our existing beliefs about justice and morality. The example does not in itself prove that the BP is correct. There are three types of possible responses: 
1) Accept the force of the example and accept that it is a case where BP applies.

2) Accept the force of the example but deny that BP applies.

3) Deny the force of the example.

If a respondent falls into the (1) camp, the job of persuasion is done, and we can move onto discussion relating to limitation. A type (2) response does not deny the persuasive force of the example in terms of the existence of a moral duty, but denies that it is the involuntary receipt of benefits which has grounded the duty. A discussion of this sort can proceed in what is, in theory, a resolvable fashion - we can determine whether the example successfully isolates the variable of involuntarily benefiting from, without contributing to, wrongdoing without involving any other moral reason which might ground the obligation in question. If such an objection succeeds, we either construct an alternative, better example, or admit defeat and concede that we cannot come up with a case where the BP holds. What, however, of disagreements in the (3) category? Should we simply conclude that the BP is inherently controversial, that it makes sense to some, but not to others, and that there is a real divide here between different outlooks on morality? Such a conclusion would be over-hasty. There is more that the defender of BP can do to try to win over the (3) advocate.

First, there is a job of work to be done in terms of trying to explain the moral force behind BP. It is not sufficient to ground a principle to say that it appears to be endorsed in particular contexts - we need to say more about the reasons why it might be adopted to explain its moral force. The key idea behind BP can be articulated as an aversion to taking advantage of wrongdoing - a particular instance of the thought that, as Thomas Pogge writes, "we should not take advantage of injustice at the expense of its victims" ${ }^{11}$ The crucial claim of the BP is that taking advantage of others in this way need not be an active act, it can consist of a passive refusal to give up benefits. It is true that the receipt of the benefit is non-voluntary, but the decision not to give up the benefit is fully voluntary, and represents an act of moral wrongdoing. This need not deny that there is a distinction between acts and omissions here, it still may be maintained that it is morally worse actively to accept 
benefits, so long as it is also accepted that one can act wrongly simply by failing to disgorge an involuntarily received benefit, in the same way that one might hold that robbing a store is worse that the (still blameworthy) act of failing to act to prevent a store being robbed. There is an intuitive response which the $\mathrm{BP}$ tries to capture which holds that a failure to give up in compensation certain benefits accruing from the wrongdoing of another makes one compliant in, and or at least, not sufficiently opposed to, the wrongdoing. This has been expressed in different ways by different authors. Axel Gosseries, for example, has described the phenomenon as being that of a "morally objectionable free rider" ${ }^{12}$ I have argued that the duty to compensate can be seen as emanating from one's condemnation of the wrongdoing in question, that our moral agency requires us to demonstrate an aversion to wrongdoing, and a commitment to the reversal of its effects. ${ }^{13}$ The claim is that there is an inconsistency in our moral outlook if we condemn actions which harm others as wrong, and so maintain that they should not have taken place, but then refuse to perform actions within in our power which would make the actual world closer to a world where the wrongdoing did not occur and which do not leave ourselves worse off than we would have been had the wrongdoing not taken place. ("I am sorry that the neighbourhood bully stole your ball and threw it over my fence. He should not have done that, and I wish that he had not done so. It is wrong that you now do not have your ball. No, you cannot have it back.") This kind of argumentation is needed for a full account of the BP, and it may be persuasive to some, though it might also be described as trying to explain why some have a particular moral intuition, rather than providing reasons which are likely to lead others to change their mind. There is doubtless scope for further work in this vein. Nonetheless, what follows focuses on a different strategy, which tries to find common ground with those who accept that there is some kind of moral issue in play in the example above, but deny that this results in the beneficiary acquiring a moral obligation to rectify injustice. The idea here is that there might be two related issues which lead to the "wrong" intuitive response to the example, which might be clarified and potentially removed by further exposition and explanation. 
Let us return to the peacock example. One obvious response under (3) is to deny that there is any question of binding morality involved in the example. Such a move can clearly accept that there is moral goodness in repaying the neighbour, but it maintains it is supererogatory, above the call of duty, in moral terms. On this view paying the money is a good thing to do and shows a fine moral character, but the appropriate analogy is with individuals who give money to charity: they are fine upstanding citizens, but this does not mean those of us who fail to act in this way are guilty of violating a moral obligation. What to make of such a response? Do we think that the individual who refuses to repay the neighbour is straightforwardly in the same moral category as someone who has not been involved in such an incident? Or is there an issue of morality in play in that there is something not good about not repaying the money? It is not clear what can be said to someone who maintains that there is simply no moral issue here. Perhaps this is just a genuine, deep disagreement. But reconciliation may be possible with those who specifically wish to resist the attribution of a moral obligation to the innocent beneficiary. My claim in what follows is that we can accommodate the essential elements of the BP within a framework which need not make reference to moral obligations per se, and that such a move helps not only with the persuasion but also the limitation problem.

First, the problem might simply be semantic in connection with the use of the word "obligation" rather than "duty", rather than relating to genuine disagreement as to the binding character of the responsibility to pay. One might accept the existence of a rectificatory duty but not an obligation if one believes that obligations by definition can only come about as a result of voluntaristic actions which arise from an individual's agency, such as promise making - the original case of obligation from which the word is derived. ${ }^{14}$ Insofar as the dispute is semantic, nothing is lost if the BP is rephrased to replace the word "obligations" with "duties". The real issue here concerns those who oppose the claim that there a moral obligation to repay because they believe that what is owed is in some sense less than an obligation, rather than akin to but not accurately described as an obligation. Is it possible to deny that the involuntary receipt of the benefit gives rise to a binding obligation (or 
equally binding duty) but nonetheless end up in a position which is sympathetic to the spirit of the $\mathrm{BP}$ insofar as it accepts that there is something wrong with not repaying?

It may be helpful at this point to consider a different sort of case of the involuntary acquisition of moral obligations: that of easy rescue situations. Suppose there is an innocent individual in mortal danger, whom I can rescue at zero risk or cost to myself, but for whose plight I am not responsible. Do I have a moral obligation to assist? For many, it is obvious that I do, and something like the following holds:

Rescue Principle (RP): In a situation where an individual can be rescued from an imminent threat of death by another moral agent, and where there is no cost to the potential rescuer in so acting, nor any other morally significant reason for the rescuer to refrain from acting, the potential rescuer has a moral duty to rescue the endangered individual.

Many writers who put forward explicitly relational accounts of distributive justice, which apply when individuals interact with one another in particular ways such as cooperating for mutual benefit, are willing to accept the existence of "natural duties of justice" to assist those in dire need, even in the absence of any prior interaction between rescuer and rescue. Rawls describes a natural duty "to help another when he is in need or jeopardy, provided that one can do so without excessive risk or loss to oneself", and holds that such duties "apply to us without regard to our voluntary acts". ${ }^{15}$ For others, however, such cases represent the most testing challenge to what we might term the "voluntarist principle": the claim that agents can only acquire special obligations to others as a result of actions which they voluntarily perform, such as entering into contractual relationships, or wrongfully causing harm. In its simple form it straightforwardly denies the claim that individuals face obligations to assist those in need, even in easy rescue cases, on the basis that such obligations would violate individuals' self-ownership. As such, it has been affirmed in various forms by both left and right libertarians. 
Suppose, for the sake of argument, that we accept the voluntarist principle, and so are committed to the claim that the RP, and, by extension, the $\mathrm{BP}$, cannot hold. There is no moral obligation to rescue those in dire need, even if it is costless to do so. It does not follow that there is there nothing else to be said about the morality of the situation. Consider, for example, the following passage from Jeffrie Murphy, specifically concerned with the question of whether a failure to act in easy rescue cases violates the rights of those whom we fail to rescue: ${ }^{16}$

I can be highly morally lacking even in cases where I violate no one's rights. For example, I am sitting in a lounge chair next to a swimming pool. A child (not mine) is drowning in the pool a few inches from where I am sitting. I notice him and realize that all I would have to do to save him is put down my drink, reach down, grab him by the trunks, and pull him out (he is so light I could do it with one hand without even getting out of my seat). If I do not save him I violate no rights (strangers do not have a right to be saved by me) but would still reveal myself as a piece of moral slime properly to be shunned by all decent people. ${ }^{17}$

It does not seem to be the case that performing the rescue is on a par with charitable giving: if we are happy to say that the non-rescuer is a "morally lacking" piece of moral slime who should be shunned by all decent people, then we are willing to place moral blame upon him. Blame here is (in Strawsonian terms) a negative reactive attitude arising from an action for which we hold an agent morally responsible: as Neil Levy writes, "To say that an agent is morally responsible (for an act, omission or attitude) is to say that... it is appropriate for observers to have certain attitudes in relation to her and her act, especially the attitudes, partly cognitive and partly constituted by emotion, of praise and blame." ${ }^{18}$ Insofar as we blame the non-rescuer it seems that we believe he has done something wrong: he should have acted in one way, but in fact acted in another. If that is right, why would we not accept that he has violated a moral obligation? The most obvious response is that the use of the term "obligation" invokes the language of enforceability. A moral obligation obligates us, it describes an action that we must perform to retain our integrity as a moral agent. It is similar to a legal obligation, insofar as this is an action we must perform to retain our status as law- 
abiding citizens. The idea of a legal obligation characteristically entails a commitment to enforceability: if I fail to fulfill a legal obligation, there is a presumption that the state is justified in employing its monopoly of legitimate coercive force against me. Some moral obligations are indeed enforceable by other agents. This is obviously true in the case of obligations to avoid causing serious harm to others: if I threaten to shoot someone for my own personal satisfaction, it is generally held to be morally acceptable to use physical force against me. It is not, however, inherent in the idea of a moral obligation that it can be enforced in this way: if I promise you I will stand on one leg for an hour it may be that I have a moral obligation to try to do so, but neither you nor anyone else is justified in using force to compel me if I go shopping instead. A given moral obligation may be enforceable or non-enforceable, and this characterization may make a difference to whether it is believed that it can be acquired non-voluntaristically. Peter Vallentyne distinguishes between two variants of self-ownership which might be endorsed by libertarians: full political self-ownership, and full interpersonal self-ownership. ${ }^{19}$ Advocates of the latter are committed to the claim that there cannot be duties to aid others other than as a result of voluntarily undertaken actions, whereas advocates of the former need only maintain that there are no such enforceable moral duties. This means that advocates of political self-ownership need not deny the claim that individuals can involuntarily acquire moral duties to assist others. If one accepts that there are both enforceable and non-enforceable moral obligations, and believes that the voluntarist principle only prohibits the involuntary acquisition of enforceable obligations, there is no objection to maintaining that individuals face a non-enforceable moral obligation to carry out easy rescues. ${ }^{20}$

Returning to the peacocks, there are two reasons why the idea of enforceability may affect the intuitive responses of (3) advocates who accept there is a moral issue in play but do not want to endorse BP. First, they may be advocates of political self-ownership, and so be opposed to the idea that it is possible to acquire enforceable moral obligations by the involuntary receipt of benefits. Alternatively, the response may be triggered by a more general unease about the practical 
effects of allowing the involuntary acquisition of enforceable moral obligations on the part of beneficiaries, even if one does feel that, in the specified example, it may be justifiable. The worry is that other cases may not be so straightforward, and allowing BP in this case may result, in practice, in situations where individuals are forced to compensate victims in a way which leaves them worse off than they would have been had the wrongdoing never occurred. ${ }^{21}$ This, ultimately, is the 'doctrine altogether new and quite untenable' that agitated Hume: that the mere receipt of unsolicited "benefits", which may not even be truly beneficial in net terms after payment was made, could give rise to enforceable obligations in law.

It is important to distinguish two different issues here. One is whether the kind of obligation incurred under the BP is the kind of obligation which could justifiably be coercively enforced by a third party were the beneficiary to refuse to fulfill it. The second is whether it would be justifiable, or desirable, for the state, specifically, to use the law to enforce such obligations even if they are, in theory, justifiably enforceable. These are not the same question, since one could coherently believe the state to be justified in enforcing BP obligations if it was able to do so without making beneficiaries net victims, but also believe that it would likely not be able to make such nuanced judgments in practice, meaning that such laws should not in fact be institutionalized. The justifiability of enforceability itself, as well as the legitimate institutionalization of enforceability, is left as an open question by the BP, though it is often held that obligations which relate to rectificatory justice, and in particular which have distributive effects, are indeed enforceable. As expressed, however, the BP takes no stance on this issue. It is possible for those concerned by enforceability to accept the existence of a moral obligation to compensate, but to deny the state or any other agent a role in ensuring that such compensation does indeed occur, be it for reasons of principle or practicality. 
With enforceability put to one side, what is the content of the moral obligation in BP? One way to express the idea is as follows: to say we have a moral obligation to compensate means that the moral reasons we have to act are sufficiently weighty that we would be doing something blameworthy if we failed to do so. Such a characterization of a moral obligation makes no claim about what can be done to make us act, but does maintain that there is more going on than simply a morally neutral failure to perform a supererogatory action. As Joseph Raz has written, "Blameworthiness is a broad category, encompassing all wrongdoing for which we are responsible and not excused."22 This idea of blameworthy conduct for which we are morally responsible is sufficient to carry most of the weight of BP - it means that the beneficiary should act, and does something wrong if she does not. If the advocate of (3) is willing to say something substantially negative about the unwilling beneficiary, this is sufficient to ground a modified version of BP:

Modified Beneficiary Principle (MBP): Agents can be morally blameworthy for failing to disgorge in compensation benefits which they involuntarily receive as a result of wrongdoing which harms other agents.

If one accepts MBP, the natural conclusion would seem to be that agents in such cases should, morally speaking, disgorge benefits and compensate the victims of wrongdoing. Whether or not this is expressed in the language of obligation with enforceability to one side is largely a semantic issue.

\section{Limitation in relation to the BP}

The previous section argues that if we wish to persuade those initially unmoved by peacock-style examples of the force of the $\mathrm{BP}$, it may help to move away from the language of moral obligation or, at least, to be specific about the understanding of moral obligation in play - and instead focus on the strength of moral reasons which we have for acting in certain ways when we receive benefits. This final section sketches how such an approach may help with the second problem facing advocates of the BP: how to specify and limit the cases of benefiting from wrongdoing where agents 
should give up some or all of the benefits they have received. The idea is that the relation of an agent to a specific act of wrongdoing makes a difference to the strength of the moral reasons the agent has to compensate. In some cases the reasons will not be sufficiently strong for us to conclude that the agent would be doing something wrong, as opposed to failing to do something good, in not acting; in other cases, the reasons go significantly past the threshold for moral obligation, meaning the agent would be seriously culpable in failing to act. In broad terms, the claim is that a prima facie case for disgorging benefits in compensation is created when an agent benefits and another suffers from what are sometimes termed the "automatic effects" of wrongdoing. ${ }^{23} \mathrm{~A}$ wrongful act can have negative and positive effects on a wide range of people: each appreciable effect on a given agent is likely to have knock-on effects on other agents with whom she interacts, affecting their life choices, purchasing and consumption, and so forth. Such problems are not limited to the BP. They are familiar in general accounts of rectificatory justice, when we ask to what extent wrongdoers should compensate those who are negatively affected by their actions, given that the actual effects might end up being vast in scope, and the BP can piggyback on whatever answer is given in such cases. The claim is that a potential case for compensating emerges when a victim suffers a setback to her interests which would ordinarily best be put right by the perpetrator of wrongdoing, but where the wrongdoer is unable so to act (because she is dead, because she lacks the means to do so, because doing so would reduce her below some minimal threshold of decency, or so forth). ${ }^{24}$ In such cases, the moral reasons beneficiaries have for acting are strong enough to hold that they face a moral obligation to disgorge benefits up to the point where the victim is no longer disadvantaged by the wrongdoing in question. To fail to do so would be to take unfair advantage of wrongdoing, and this is incompatible with retaining our integrity as moral agents. The fact that the victim's losses stem from wrongdoing specifically makes the moral reasons for acting particularly weighty. Depending on the nature of the wrongdoing, they may be weightier still. I have previously made reference to the category of cases where the purpose behind an act of wrongdoing is the conferral of a benefit on a particular involuntary beneficiary. ${ }^{25}$ Suppose that, in the peacock example, it was my mother who 
substituted the note specifically in order to benefit me. She subsequently disappears, leaving behind no assets. It seems very hard to maintain that it is reasonable for the beneficiary to shrug their shoulders and say, "I didn't ask for this hedge to be cut. Sorry for your loss, but I'm keeping the money." Assuming that background property holdings are legitimate, and that there is no pressing reason for the beneficiary to retain the money other than their own self-interest, this seems to take us into moral slime territory.

Everything said hitherto has referred to benefits stemming from wrongdoing. We can now note, however, how a modified version of the preceding argument might be applied to a much wider range of involuntarily received benefits. I have maintained that benefits stemming from wrongdoing are a special case, that the moral reasons for compensating victims to which they give rise are especially weighty. Losses caused by wrongdoing have a particular character, and arguments can be made in relation to them which do not necessarily apply to other setbacks to people's interests. But it might still be that we have moral reasons to disgorge benefits which result from different instances of others suffering losses in ways which advantage us. Candidate cases of such losses include those caused by the non-culpable actions or omissions of others, performed, for example, in ignorance of their effects (such as, arguably, some historic greenhouse gas emissions), and those caused by accidents of brute bad luck. In both cases, an argument can be made that it is wrong to take advantage of the losses which others have suffered through no fault of their own by failing to compensate victims. The same kind of questions can be asked as in the wrongdoing case: we look at examples where individuals are benefited by losses of the relevant type, and ask ourselves how we view the morality of the situation: would it just be morally good but supererogatory to compensate the victims, or is there a more weighty moral issue in play? Such an argument would need a different rationale from the wrongdoing account outlined above, but it is clear how it could be developed if we accept, for example, that it is regrettable that people suffer unanticipated losses through no fault of their own, It can be seen how such a judgment could come into tension with a belief that there is 
nothing wrong in failing to give up a benefit which emerges from another's misfortune when the connection between loss and benefit is sufficiently obvious.

More controversially, the form of this approach can be applied to other cases where an individual involuntarily receives a benefit as a result of the deliberate actions of an individual who hopes to gain something, such as payment, in return. Suppose that someone does act in such a way, conferring what I accept is a significant benefit upon me, which I was not given the opportunity to reject. How should we describe the moral relationship between service provider and beneficiary in such a case? The problem with our intuitive response to such examples is that there is any number of objections which might be raised against allowing businesses to operate in such a fashion, which is likely to colour our initial reaction to the idea that the beneficiary "should" pay the provider. We may fear situations where vulnerable people are pressured into paying in a way that leaves them worse off overall than if they had not received the service, or perhaps do not wish regularly to be placed in the awkward position of declining to pay for a service which has been provided but from which we do not feel we have benefited. We may simply feel that there is a lack of respect, or even an infringement of our autonomy, in advancing our interests without our prior consent, even if we accept that our interests have indeed been advanced. Robert Goodin has spoken in this context of the lack of respect for autonomy involved in "forcibly push [ing] people along their indifference curves $^{\prime 26}$ - it matters, from a moral perspective, that we are the authors of our own destiny and that the paths our lives take reflect decisions we have ourselves made, even if choices others might make for us might leave us better off than we would otherwise have been. But suppose we try to imagine a morally unproblematic business which operates in this way - conferring benefits, and then asking, nicely, for payment. Perhaps the local branch of the Girl Guides is trying to raise funds to go camping, and so spends an afternoon clearing up the park in the middle of the square, before dropping notes through letterboxes requesting that those who feel they have benefitted from their actions might consider making an anonymous donation. We can agree with Hume that it would be wrong to ground a legal obligation to pay in such cases, such that the company could sue those to 
whom it had provided services. Who is the state, after all, to judge who has or has not actually acquired a net benefit from the service in question? Perhaps I preferred the park the way it was. But it does not necessarily follow from this that we are now in the domain of supererogation. There is at least potential here for an argument that maintains that there is something wrong with failing to pay in a case where the customer has received a manifest benefit on their own evaluation, and the business has paid substantial costs, even if we do not think that the reasons for paying are sufficiently strong to obligate us in either an enforceable or a non-enforceable sense. More, of course, would need to be done to articulate the moral principle lying behind such a position, which is not so easily expressed in terms of a prohibition against taking unfair advantage as in the wrongdoing, non-wrongful injustice, and bad brute luck cases, since it is others' voluntary actions which have given rise to their potential loss. What does seem clear is that if one believes that there is a case for maintaining that there are moral reasons to pay which go beyond the supererogatory, this is likely to be most persuasive to others if it is not phrased in the language of obligation.

\section{Conclusion}

This article started by noting the relevance of the BP to significant policy debates, such as reparations for colonialism, affirmative action, and climate change. It might be thought that the moves away from enforceability and the language of obligation which were made to motivate possible widespread support for the MBP undermine the practicality of the beneficiary pays principle in the real world. This is not my intention. I have previously argued that there are good reasons to think that BP is not a good candidate for a principle which can, in practice, be enshrined in law and made legally enforceable due to the subjective welfare element in individual calculations of harm and benefit - there is no obvious way that an outside party can determine the extent to which an agent benefits from involuntarily receiving a benefit when this turns on the individual's attitude to this benefit, which cannot be authoritatively determined from the outside. ${ }^{27}$ I therefore presented the BP as an element of an agent-centred morality, arguing that agents should determine 
what they owe to others based on their own evaluation of the extent to which they have benefited from wrongdoing. This may be a useful way of thinking about the BP when dealing with small-scale cases such as the hedge example: different people evidently have different preferences in relation to topiary. However, it might be that the use of such fanciful examples actually undermines the broader persuasive force of the BP, given that the real world cases where it is potentially significant do not typically involve neighbours' hedges and evil note switchers. Concerns of subjectivity as to the value of purported benefits may be much less significant when the BP is invoked in relation to large collectives. In such cases, it seems much more straightforward to maintain that particular consequences of past injustice, such as increases in general prosperity and rises in national life expectancy, or the accrual of competitive advantages on the employment market, have been beneficial to particular groups as a whole, and so a more compelling case for the legal institutionalization of the principle can be made. Similarly, it may well be that even if we feel that obligations acquired under the BP are not justifiably enforced by the state when they target particular individuals, the situation is different when a community debates in its democratic fora whether it should hold itself collectively liable cost for the actions of its predecessors. My aim in this article has been to counter a common move against the applicability of the BP in such cases which straightforwardly denies that involuntarily benefiting from the wrongful actions of others can, in itself, give rise to moral duties to others. I have sought to show both why I feel that this reaction is unjustified, but also why I think it is commonplace. Accepting that the BP, or even the MBP, can apply in some cases is sufficient to give at least some moral weight to the idea that benefiting from injustice can lead to compensatory duties to others. Once that principle is established, it can play a potentially important role in political debates as to the fair distribution of benefits and burdens both within and between different communities.

Daniel Butt, Balliol College, Oxford, OX1 3BJ, United Kingdom. daniel.butt@politics.ox.ac.uk 


\section{Acknowledgements}

I am grateful to reviewers for the Journal of Applied Philosophy and audiences at the Uppsala Forum Workshop on Unjust Benefits at the University of Uppsala, the Cabot Institute Environmental Ethics and Regulation Workshop at the University of Bristol, and the School of Politics and International Relations at University College, Dublin for their helpful comments on this paper. I would particularly like to thank Robert Goodin, Robert Huseby, Kieran Oberman, Edward Page, and Avia Pasternak.

\footnotetext{
${ }^{1}$ See, for example, Judith Jarvis Thomson, 'Preferential hiring', in Rights, Restitution and Risk: Essays in Moral Theory (London: Harvard University Press, 1986), 135-53; Daniel Butt, 'On benefiting from injustice', Canadian Journal of Philosophy 37(2007): 129-52 and Rectifying International Injustice: Principles of Compensation and Restitution Between Nations (Oxford: Oxford University Press, 2009), pp.117-139; and Edward Page, 'Climatic justice and the fair distribution of atmospheric burdens', The Monist 94 (2011): 412-32, respectively.

${ }^{2}$ See Norbert Anwander, 'Contributing and benefiting: two grounds for duties to the victims of injustice', Ethics and International Affairs 19 (2005): 39-45; Nahshon Perez, Freedom from Past Injustices (Edinburgh: Edinburgh University Press, 2012).
}

${ }^{3}$ Michael Sandel, Justice: What's the Right Thing to Do? (London: Penguin, 2009), p.147.

${ }^{4}$ See Robert E. Goodin, 'The state as a moral agent' in Utilitarianism as a Public Philosophy (Cambridge:

Cambridge University Press, 1995), 28-44.

5 Jeremy Waldron, 'Superseding historic injustice', Ethics 103 (1992): 4-28.

${ }^{6}$ See G. A. Cohen, If You're an Egalitarian, How Come You're So Rich? (Cambridge, MA: Harvard University Press, 2000).

${ }^{7}$ See Peter Singer, 'Famine, affluence and morality', Philosophy and Public Affairs 1 (1972):229-43; Liam Murphy, Moral Demands in Nonideal Theory (Oxford: Oxford University Press, 2000).

${ }^{8}$ For such a claim, see Robert E. Goodin "Disgorging the fruits of historical wrongdoing", American Political Science Review 107 (2013): 478-491.

${ }^{9}$ Robert Fullinwider 'Preferential hiring and compensation', in Steven M. Cahn (ed), The Affirmative Action Debate (New York: Routledge, 2002), pp.75-6. Fullinwider's original example involves repaving a driveway rather than cutting a hedge, and it is this example I originally discussed in 'On benefiting from injustice' (2007). 
I have changed this detail to avoid the problem of the ownership of the materials used in the driveway's repair.

${ }^{10}$ Some readers have suggested to me that the fact that I have actually written a letter is important, as it represents a kind of quasi-contract even in its unposted state. (For relevant discussion, see Robert Huseby, 'Should the beneficiaries pay?', Politics, Philosophy \& Economics: forthcoming.) I do not accept this, but should this be taken to be problematic, consider the following alternative. My neighbour contracts to have her hedge cut as in the prior example, but my hedge is cut instead, while I am on vacation. Returning, I see my hedge. As I knew my neighbour was planning on having her hedge cut and as I previously had no plans to have my own hedge cut, I do not notice that the hedge is in my garden, and mistakenly believe that it is in fact her hedge. "What a splendidly cut hedge!", I think to myself, "I wish my hedge looked like that! I wonder how much it cost. If it is less than $f 2,000$, I shall ask the same company to cut my hedge." A further possibility is the thought that I have special communal obligations to my neighbour that I do not owe to others: clearly the example can be tweaked so that the victim of wrongdoing is a person unknown to me who lives some distance away.

${ }^{11}$ Thomas Pogge, 'Assisting the global poor', Proceedings of the Twenty-First World Congress of Philosophy 13 (2007): 189-215.

${ }^{12}$ Axel Gosseries, 'Historical emissions and free-riding', Ethical Perspectives 11 (2004): 38-62.

${ }^{13}$ Butt (2007) op. cit., p. 143.

${ }^{14}$ For discussion, see H. L. A. Hart 'Legal and moral obligation' in A. I. Melden (ed.) Essays in Moral Philosophy, (Seattle: University of Washington Press, 1958), 82-107; Richard Brandt, "The concepts of obligation and duty", Mind 73 (1964): 374-93; George Klosko, The Principle of Fairness and Political Obligation (Lanham: Rowman and Littlefield, 2004), 6-10.

15 John Rawls, A Theory of Justice (Oxford: Oxford University Press, 1972), p.114.

${ }^{16}$ I take this passage to be indicative of the attitude to easy rescue cases for those who deny the existence of moral obligations to assist, but clearly Murphy is not committed here to the claim that there is no moral obligation to assist, merely that there is no correlative right to be rescued.

${ }^{17} J$ effrie G. Murphy, “Blackmail: a preliminary inquiry,” The Monist 63 (1980): 156-171 at p168, n6.

${ }^{18}$ Neil Levy, "The good, the bad and the blameworthy", Journal of Ethics and Social Philosophy 1 (2005): 2-16

at p.2. See P. Strawson, "Freedom and resentment", Proceedings of the British Academy 48 (1962): 1-25. 
${ }^{19}$ Peter Vallentyne, "Libertarianism" in Edward N. Zalta (ed.), The Stanford Encyclopedia of Philosophy (Spring 2012 Edition) (2012): <http://plato.stanford.edu/archives/spr2012/entries/libertarianism/>.

${ }^{20}$ David Miller's account of a "humanitarian obligation" to assist those in dire need has this character. Miller, "Taking up the slack? Responsibility and justice in situations of partial compliance", in C. Knight and Z. Stemplowska (eds.), Responsibility and Distributive Justice (Oxford: Oxford University Press, 2012), 230-245 at pp.243-4.

${ }^{21}$ Essentially the same point is made in Gosseries op. cit., p.48.

${ }^{22}$ Joseph Raz, "Agency and luck", in Ulrike Heuer and Gerald Lang (eds.), Luck, Value, and Commitment: Themes from the Ethics of Bernard Williams (Oxford: Oxford University Press, 2012), 133-162 at pp.155-6.

${ }^{23}$ See, George Sher, 'Ancient wrongs and modern rights', Philosophy and Public Affairs 10 (1980): 3-17 at p.13.

${ }^{24} \mathrm{My}$ assumption here is that, in the non-ideal circumstances outlined in Section 1, we generally hold that offenders should bear primary responsibility for rectifying such harm, but that there are circumstances where it is appropriate to allocate costs to other agents. I follow here the "connection theory" developed by David Miller in National Responsibility and Global Justice (Oxford: Oxford University Press, 2007), pp.102-3; for further discussion, see Butt (2007) op. cit., p.142.

${ }^{25}$ Butt (2007) op. cit., pp. 145-6.

${ }^{26}$ Robert E. Goodin, “Theories of compensation", Oxford Journal of Legal Studies 9 (1989): 56-75 at p.70.

${ }^{27}$ Butt (2007) op. cit., pp. 149-51. 